\title{
Type I error control in biomarker-stratified clinical trials
}

\author{
Deepak Parashar ${ }^{1 *}$, Jack Bowden², Colin Starr ${ }^{2}$ Lorenz Wernisch², Adrian Mander ${ }^{2}$ \\ From 3rd International Clinical Trials Methodology Conference \\ Glasgow, UK. 16-17 November 2015
}

Biomarker-stratified clinical trials assess the biomarker signature of subjects and split them into subgroups so that treatment is of benefit to those who are likely to respond. Since multiple hypotheses are tested, it becomes important to control the type I error. Current methods control the false positive rate where one rejects the null hypothesis while in reality that was true. For two subgroups, the false positive rate is controlled across the two hypotheses as a Family Wise Error Rate (FWER) to an overall predetermined significance level.

The concept of "Wrong Positive" rate is presented where one rejects the null hypothesis in one subgroup while in reality the efficacy would be in the other subgroup. Controlling the wrong positives as well as false positives to an overall significance level constitutes a strong FWER. Further options exist for control of Individual Outcome FWER by assigning weighting to reject the respective null hypotheses.

We apply our methodology to an optimal biomarkerstratified Simon two-stage cancer clinical trial design and illustrate the variation in minimum expected sample sizes for different choices of type I controls for a range of operating characteristics. While the weak FWER would suit a phase II trial, additionally controlling the wrong positives could be more appropriate in a confirmatory setting. The chosen design is an adaptive enrichment that evaluates efficacy in biomarker-positive as well as biomarker-negative subpopulations, and optimal designs are obtained using the four different choices of type I error controls: weak or strong FWER with or without individual outcomes.

Authors' details

${ }^{1}$ University of Warwick, Coventry, UK. ${ }^{2}$ MRC Biostatistics Unit, Cambridge, UK.

${ }^{1}$ University of Warwick, Coventry, UK

Full list of author information is available at the end of the article
Published: 16 November 2015

doi:10.1186/1745-6215-16-S2-084

Cite this article as: Parashar et al: Type I error control in biomarkerstratified clinical trials. Trials 2015 16(Suppl 2):O84.
Submit your next manuscript to BioMed Central and take full advantage of:

- Convenient online submission

- Thorough peer review

- No space constraints or color figure charges

- Immediate publication on acceptance

- Inclusion in PubMed, CAS, Scopus and Google Scholar

- Research which is freely available for redistribution

Submit your manuscript at www.biomedcentral.com/submit
() Biomed Central
() Biomed Central

(c) 2015 Parashar et al. This is an Open Access article distributed under the terms of the Creative Commons Attribution License (http:// creativecommons.org/licenses/by/4.0), which permits unrestricted use, distribution, and reproduction in any medium, provided the original work is properly cited. The Creative Commons Public Domain Dedication waiver (http://creativecommons.org/publicdomain/ zero/1.0/) applies to the data made available in this article, unless otherwise stated. 